\title{
HISTOPATHOLOGIC PATTERN OF GASTRIC CARCINOMA IN BANGLADESH
}

\author{
Islam $\mathrm{SMJ}^{1}$, Ali $\mathrm{SM}^{2}$, Ahmed $\mathrm{S}^{3}$, Afroz QD ${ }^{4}$, Chowdhury $\mathrm{R}^{5}$, Huda $\mathrm{M}^{6}$
}

\begin{abstract}
Incidence of gastric carcinoma as well as other gastric malignancies is increasing day by day in the whole world as well as in Bangladesh. Prevalence of Helicobacter pylori in this country is an important contributing factor in this increasing trend of gastric malignancies. A study was carried out at the Department of Histopathology, Delta Hospital Limited, Dhaka to find out patterns of gastric malignancies in Bangladesh. All endoscopic gastric biopsy received during the stipulated period from January to December 2007, irrespective of age, sex and clinical suspicion, samples were included in the study. During the period total 1543 gastric biopsy samples were received, which were $7.95 \%$ of all the received (19410) samples. The endoscopic gastric biopsy samples were received from almost all the geographic locations of Bangladesh. Among those $5(0.3 \%)$ samples were discarded from the study due to superficial inadequate biopsy.
\end{abstract}

Out of 1538 cases $636(41.35 \%)$ cases were malignant neoplasm of stomach, $493(32.05 \%)$ were chronic active gastritis, $150(9.75 \%)$ were chronic gastritis with intestinal metaplasia, 208 (13.52\%) were chronic peptic ulcer, $48(3.12 \%)$ were gastric polyp and 11 (0.72\%) others. Among 636 gastric malignancies 625 $(98.27 \%)$ were gastric adenocarcinoma and 11 (1.73\%) were non Hodgkin's lymphoma. Most 357 $(57.12 \%)$ of the gastric adenocarcinomas were poorly differentiated, $80(12.8 \%)$ were well differentiated and $84(13.44 \%)$ were moderately differentiated. Out of 625 cases, $104(16.64 \%)$ cases were mucin secreting adenocarcinoma. Out of 11 Non Hodgkin's Lymphoma cases 10 were male and 01 was female. For adenocarcinoma male and female ratio was 2.36:1.

Among the gastric carcinoma group the youngest person affected was of $\mathbf{1 6}$ year and the oldest person was of 100 year with the mean age 43.14 year. Among the Non Hodgkin's lymphoma group the mean age was 45 year with the range from 22 year to 65 year. Among the gastric malignancies, 275 (44\%) cases were from Chittagong division, $188(30.08 \%)$ from Dhaka division, $108(17.28 \%)$ from Rajshahi division, 58 $(9.28 \%)$ from Khulna division and others from Sylhet and Barisal division. It reflects very high incidence of gastric malignancies in comparison to other pathological changes in gastric endoscopic biopsy. It also reflects that between 16 year to 100 year no age is immune to the disease.

\section{Key Words: Histopathologic pattern, Gastric} carcinoma.

\section{Introduction}

Gastric carcinoma is the second most common tumour in the world. Its' incidence being particularly high in countries such as Japan, Chile, Costa Rica, Colombia, China, Russia, Bulgaria and four to six fold less common in USA, UK, Canada etc. It is more common in lower socioeconomic groups ${ }^{1}$ Globally, it is the second leading cause of cancer-related death, with $7,00,000$ deaths annually $^{2}$.

Epidemiology of gastric cancer has been attributed to various environmental factors which include dietary factors $^{3}$. Salt contents of soil and drinking water ${ }^{3}$, Helicobacter pylori infection ${ }^{4}$, socio-economic status ${ }^{5}$ and smoking ${ }^{6}$.

The prevalence of Helicobacter pylori infection varies markedly in different Asian countries. The prevalence rates in developing Asian countries such as Bangladesh ${ }^{7}$, India $^{8}$, Thailand ${ }^{9}$ and Vietnam ${ }^{10}$ have been reported to be especially high at $92 \%, 81 \%, 74 \%$ and $75 \%$, respectively, whereas in more industrialized and developed countries such as Japan ${ }^{11}$, Korea ${ }^{12}$ and Singapore ${ }^{13}$ the rates are somewhat lower at 39\%, 54\% and 31\% respectively.

In Bangladesh prevalence of Helicobacter pylori is very high but no country base epidemiological study has been carried out so far to find out the actual incidence pattern of gastric carcinoma. Some sporadic studies were carried out to find out the histological pattern of gastric carcinoma. This study has been designed to take effort to find out the incidence pattern as well as histological pattern of gastric carcinoma in Bangladesh.

\section{Materials and Methods}

The study was carried out at the Department of Histopathology of Delta Hospital Limited, Mirpur-1, Dhaka, a tertiary level hospital specially designed to diagnose, treat and manage the cancer patients.

The study was carried out during the period January to December 2007. All endoscopic gastric biopsy samples received during the stipulated period irrespective of age, 
sex and clinical suspicion were included in the study. In all the cases $10 \%$ formalin was used as fixative. Histopathological examination was carried out after conventional paraffin section followed by H\&E staining. In certain cases PAS staining was done. During histopathological examination samples declared as inadequate were excluded from the study.

\section{Result}

During the period total 1543 endoscopic gastric biopsy samples were received which was $7.95 \%$ of all the total received samples (19410) at the histopathology laboratory of Delta Hospital Limited, Dhaka. The endoscopic gastric biopsy samples were received from almost all the geographic locations of Bangladesh.

Among 1543 samples $5(0.3 \%)$ were discarded from the study due to tiny superficial biopsy which were declared as inadequate.

Out of 1538 cases $636(41.35 \%)$ cases were diagnosed as malignant neoplasm of stomach, $493(32.05 \%)$ were chronic active gastritis, $150(9.75 \%)$ were chronic gastritis with intestinal metaplasia, 208 (13.52\%) were

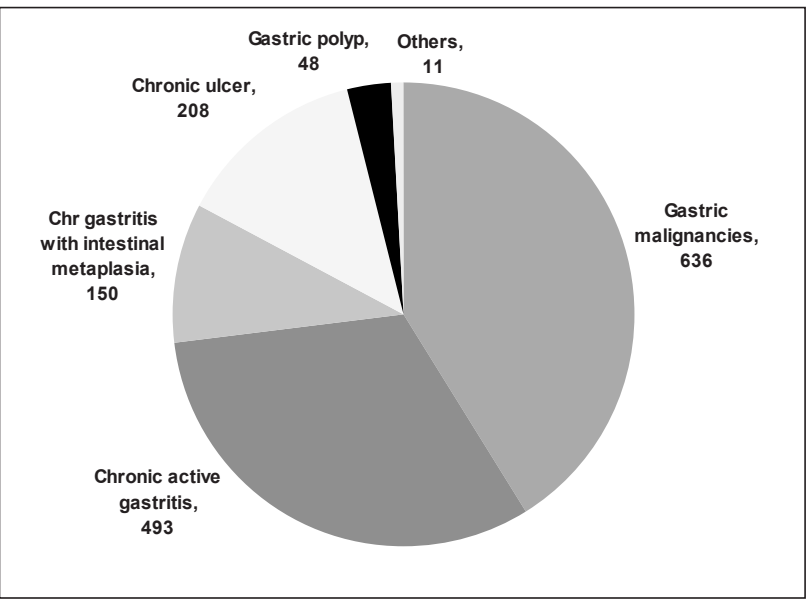

Fig-1: Disease pattern in gastric endoscopic biopsy samples $(\mathrm{n}=1538)$.

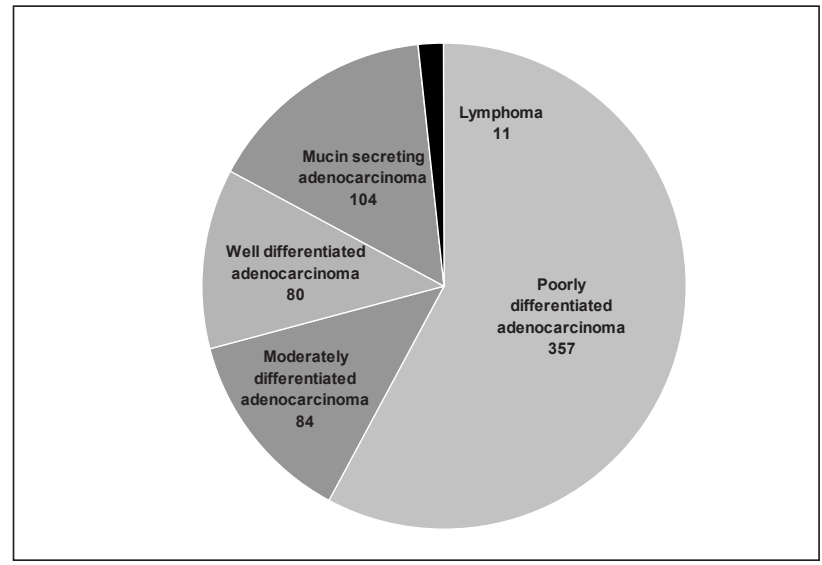

Fig-2: Patterns of gastric malignancies $(\mathrm{n}=636)$.

chronic peptic ulcer, 48 (3.12\%) were gastric polyp and $11(0.72 \%)$ others (Fig- 1$)$.

Among 636 gastric malignancies 625 (98.27\%) were gastric adenocarcinoma and $11(1.73 \%)$ were non Hodgkin's lymphoma. Among 625 gastric adenocarcinoma cases $357(57.12 \%)$ were of poorly differentiated, $80(12.8 \%)$ were of well differentiated and $84(13.44 \%)$ were of moderately differentiated. Out of 625 adenocarcinoma cases $104(16.64 \%)$ were mucin secreting adenocarcinoma and all of these were also of poorly differentiated (Fig-2).

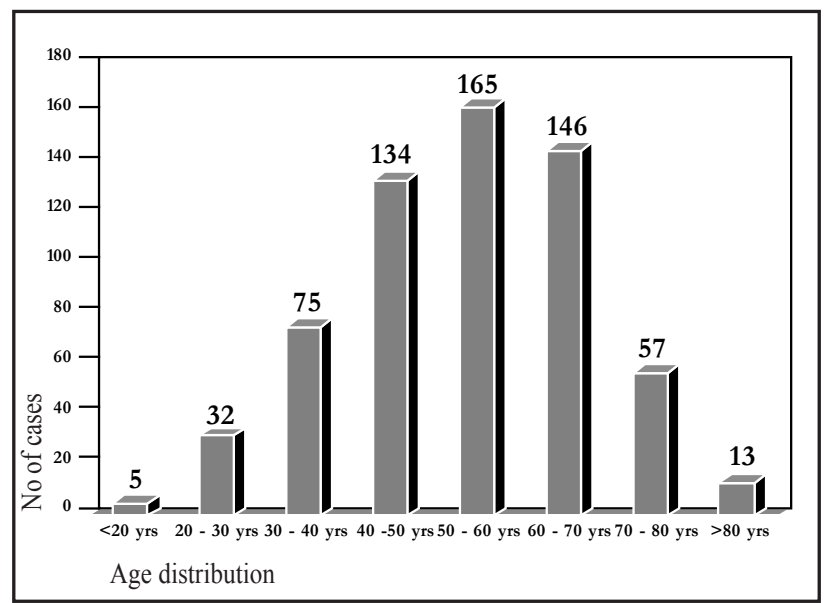

Fig-3: Age distribution for gastric adenocarcinoma $(n=625)$.

Out of 11 gastric non Hodgkin's Lymphoma cases 10 were male and 01 was female. Among the non Hodgkin's lymphoma group the mean age was 45 year with the range from 22 year to 65 year.

For gastric adenocarcinoma male and female ratio was 2.36:1. Among the 625 gastric carcinoma cases the youngest person affected was of 16 year and the oldest person was of 100 year with the mean age 43.14 year (Fig-3).

Among the gastric malignancies, 275 (44\%) cases were from Chittagong division, 188 (30.08\%) from Dhaka division, 108 (17.28\%) from Rajshahi division, 58 $(9.28 \%)$ from Khulna division and others from Sylhet and Barisal division (Fig-4).

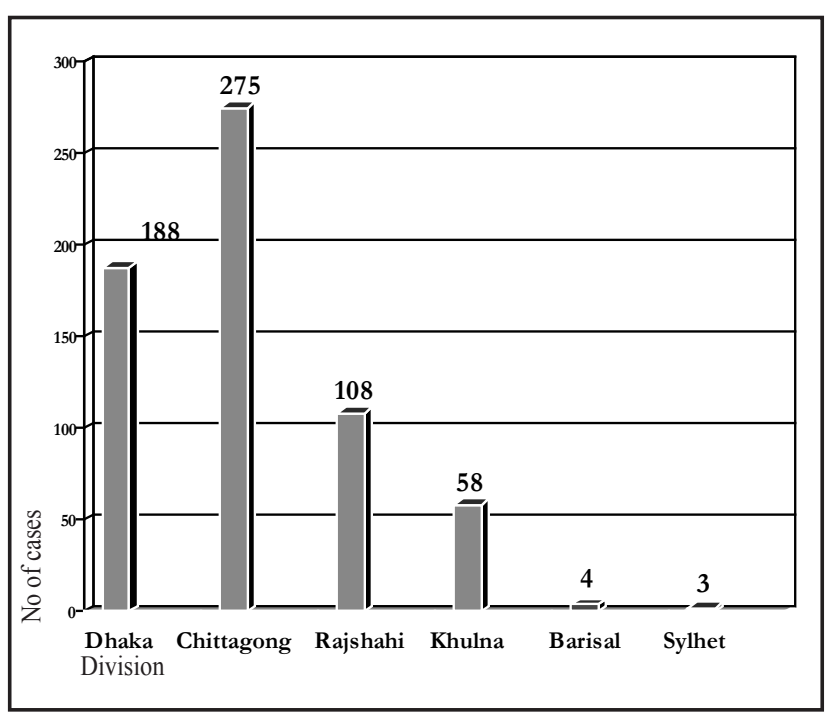

Fig-4: Geographic distribution of Gastric Malignancies $(n=636)$. 


\section{Discussion}

Gastric carcinoma has been reported to be common in developing countries or in developing sub-populations of rich countries ${ }^{14}$. It continues to carry bad prognosis world wide except in Japan ${ }^{15}$. High-risk areas include East Asian countries such as China, Japan and Korea, where the agestandardized incidence rate (ASR) is greater than 20 per 100,000. Intermediate risk countries (ASR 1119/100,000) include Malaysia, Singapore and Taiwan, while low-risk areas (ASR $<10 / 100,000)$ include countries such as Australia, New Zealand, India and Thailand ${ }^{2}$.

Currently, population-based screening is being undertaken in Japan ${ }^{16}$, Korea ${ }^{17}$ and Matsu island in Taiwan ${ }^{18}$. These are populations with high gastric cancer risks. In Japan, screening is performed in individuals aged over 40 years using double-contrast barium or endoscopy. In Korea, endoscopy is used, while in Taiwan, individuals are first screened using serum pepsinogen and, if the level is low, endoscopy is performed.

In Bangladesh no such country based screening for gastric carcinoma is carried out. Sporadically only the symptomatic patients undergo endoscopy and endoscopic biopsy are performed only if any suspicious lesion is found by the endoscopists. Delta hospital limited is a well known histopathology center situated in Dhaka, the capital of Bangladesh. From all over the country a good number of histopathological samples are forwarded here each year which cover a good number of endoscopic biopsy samples. Though it does not represent the exact incidence pattern of gastric carcinoma in Bangladesh, endoscopic gastric biopsy samples received in this center gives a part view of the state of gastric carcinoma in Bangladesh. In this study total 1543 gastric endoscopic biopsy samples were received which was $7.95 \%$ of total received samples (19410) during the period of 01 year. After exclusion of 05 unsatisfactory samples out of 1538 cases $636(41.35 \%)$ cases were diagnosed as malignant neoplasm of stomach. While Talukder SI et al got 119 (67.23\%) gastric carcinoma out of a small series of 177 gastric biopsy samples conducted at Mymensingh region of Bangladesh ${ }^{19}$. Other pathological conditions which were diagnosed on endoscopic gastric biopsy samples were chronic active gastritis 493 (32.05\%), chronic gastritis with intestinal metaplasia $150(9.75 \%)$, chronic peptic ulcer 208 (13.52\%), 48 (3.12\%) were hyperplastic gastric polyp and $11(0.72 \%)$ others.

In this study among 636 gastric malignancies most (98.27\%) of the cases were gastric adenocarcinoma and only $1.73 \%$ were non Hodgkin's lymphoma. While among the gastric adenocarcinoma cases $357(57.12 \%)$ were of poorly differentiated, $80(12.8 \%)$ were of well differentiated and $84(13.44 \%)$ were of moderately differentiated. Out of 625 adenocarcinoma cases, 104 (16.64\%) were mucin secreting adenocarcinoma. Talukdar SI et al got only gastric adenocarcinoma in malignant gastric biopsy samples, which included intestinal type $68.91 \%$, diffuse type $14.29 \%$ and others were of mixed type ${ }^{19}$.

Among the 625 gastric carcinoma cases of this study the youngest person affected was of 16 years and the oldest person was of 100 years with the mean age 43.14 years. For gastric adenocarcinoma male and female ratio was 2.36:1. In a study of California among the gastric cancer patients of south Asian population male and female ratio was $1.24: 120$. While in Japanese cancer registry annual age standardized incidence rate of gastric cancer ranges from 50 to 80 per 100,000 among men and from 20 to 30 per 100,000 among women during 1998 to $2002^{21}$. In this study out of 11 gastric non Hodgkin's Lymphoma cases 10 were male and 01 was female, the mean age was 45 years with the range from 22 years to 65 years.

Gastric malignancies are more prevalent (44\%) in Chittagong division followed by 188 (30.08\%) from Dhaka division, 108 (17.28\%) cases were from Rajshahi division, 58 (9.28\%) from Khulna division and others from Sylhet and Barisal division.

\section{Conclusion}

The study population covers almost all the geographic areas of Bangladesh. It reflects very high incidence of gastric malignancies in comparison to other pathological changes in gastric endoscopic biopsy. It also reflects that between 16 years to 100 years no age is immune to gastric malignancies.

\section{References}

1. Crawford JM. The gastrointestinal tract basic pathology. In: Kumar V, Cotran RS, Robbins ST. Robbins pathology basis of disease. 5th ed. Philadelphia: W. B. Saunders, 1994.p.490-3.

2. Parkin DM, Bray F, Ferlay J, Pisani P. Global cancer statistics 2005 CA Cancer J Clin 2005; 55: 74-108.

3. Palli D. Epidemiology of gastric cancer: an evaluation of available evidence. J Gastroenterol 2000;35 (Suppl): 84-9.

4. Helicobacter and Cancer collaborative group. Gastric cancer and $\mathrm{H}$. pylori: a combined analysis of 12 case control trials nested within prospective cohorts. Gut 2001;9:347-53.

5. Sitas F, Forman D, Yarnell JW, et al. H. pylori infection in relation to age and social class population of Welshmen. Gut 1991;32:25-8.

6. Howsen CP, Hyama T, Wyander EC. The decline in gastric cancer; Epidemiology of an unexplained triumph. Epidemiol Rev 1986; 8:1127-31. 7. Ahmad MM, Rahman M, Rumi AK, et al. Prevalence of Helicobacter pylori in asymptomatic population - a pilot serological study in Bangladesh. J Epidemiol 1997; 7:251-4

8. Ramakrishna BS. Helicobacter pylori infection in India: the case against eradication. Indian J Gastroenterol 2006; 25: 25-8.

9. Perez-Perez GI, Taylor DN, Bodhidatta L, et al. Seroprevalence of Helicobacter pylori infections in Thailand. J Infect Dis 1990; 161: 1237-41. 10. Hoang TT, Bengtsson C, Phung DC, et al. Seroprevalence of Helicobacter pylori infection in urban and rural Vietnam. Clin Diagn Lab Immunol 2005; 12: 81-5.

11. Fujisawa T, Kumagai $T$, Akamatsu $T$, et al. Changes in seroepidemiological pattern of Helicobacter pylori and hepatitis A virus over the last 20 years in Japan. Am J Gastroenterol 1999; 94: 2094-9.

12. Malaty HM, Kim JG, Kim SD, et al. Prevalence of Helicobacter pylori infection in Korean children: inverse relation to socioeconomic status despite a uniformly high prevalence in adults. J Epidemiol 1996; 143: 257-62.

13. Fock KM. Helicobacter pylori infection - current status in Singapore. Ann Acad Med Singap 1997; 26: 637-41.

14. Neuget AI . Epidemiology of gastric cancer. Semin Oncol 1996;23:281.

15. Maruyama K, Okabayashi K, Kinoshita T. Progress in gastric cancer in surgery in Japan and its limit of radicality. World J Surg 1987;11:418-25.

16. Hisamichi S. Screening for gastric cancer. World J Surg 1989; 13: 31-7. 
17. Kim YS, Park HA, Kim BS, Yook JH, Lee MS. Efficacy of screening for gastric cancer in a Korean adult population: a case-control study. J Korean Med Sci 2000; 15: 510-15.

18. Liu CY, Wu CY, Lin JT, Lee YC, Yen AM, Chen TH. Multistate and multifactorial progression of gastric cancer: results from community-based mass screening for gastric cancer. J Med Screen. 2006; 13 (Suppl. 1): S2-5.
19. Talukder SI, Ali MS, Rahman S, et al. Histopathological types of Malignant Lesions of Esophagus and Stomach. MMJ 2004/07;13(2):138-42.

20. Ratnali V J, Paul K M, Arti P P. Cancer Incidence in the South Asian Population of California, 1988-2000. Journal of Carcinogenesis 2005; 4:21.

21. Curado MP, Edwards B, Shin HR et al.,eds. Cancer incidence in five contients. Vol.9. Lyon, France: IARC Press, 2007. [http://www.-dep,iarc.fr.] 